\title{
Avaliação de treinamento em suporte básico de vida para médicos e enfermeiros da atenção primária
}

\author{
Assessment of basic life support training for primary health care doctors and nurses \\ Evaluación de la capacitación en soporte vital básico para médicos y enfermeros de la \\ atención primaria \\ Luiz Ernani Meira Júnior, Fabiane Mendes Souza, Leonardo Canela Almeida, Gilson Gabriel Viana Veloso, \\ Antônio Prates Caldeira
}

\section{Resumo}

Objetivo: Foram avaliados conhecimentos e habilidades sobre reanimação cardiopulmonar antes e após a capacitação em Suporte Básico de Vida (SBV) para médicos e enfermeiros que atuam na atenção primária. Métodos: Estudo quasi-experimental, com amostra aleatória de profissionais. Inicialmente, avaliou-se o desempenho cognitivo em um teste de múltipla escolha sobre o atendimento a uma parada cardiorrespiratória (PCR) e, em seguida, conduziu-se um atendimento simulado de PCR, para a avaliação de habilidades, usando um checklist baseado nas recomendações da American Heart Association (AHA). Após avaliação inicial, todos os profissionais participaram de curso teórico-prático em SBV, durante três encontros. Após o curso, todos se submeteram a nova avaliação. Resultados: Participaram do estudo 32 profissionais. O nível de conhecimentos e habilidades foi insatisfatório antes do curso. Após a capacitação, a média de acertos na avaliação teórico-prática apresentou aumento significativo $(p<0,001)$. Conclusão: Registrou-se impacto positivo da capacitação em SBV para os profissionais da atenção primária.

\section{Abstract}

Objective: To evaluate knowledge and skills on cardiopulmonary resuscitation before and after training in Basic Life Support (BLS) for doctors and nurses working in primary health care. Methods: A quasi-experimental study with a random sample of professionals. Initially, a cognitive performance was evaluated in a multiple choice test on assistance to a cardiopulmonary arrest (CPA) and then a simulation of CPA was carried out to assess skills, using a checklist based on recommendations of the American Heart Association (AHA). After initial evaluation, all professionals participated in theoretical and practical course in BLS in three meetings. After the course, they all underwent further evaluation. Results: The study included 32 professionals. The level of knowledge and skills was poor before the course. After the training, the mean score on the written and practical evaluation showed a significant increase $(p<0.001)$. Conclusion: It was recorded positive impact of training in BLS for primary care professionals.

\section{Resumen}

Objetivo: Se evaluó el conocimiento y las habilidades de reanimación cardiopulmonar antes y después de la formación en soporte vital básico (SVB) para los médicos y enfermeras que trabajan en la atención primaria. Métodos: Estudio cuasi-experimental con una muestra aleatoria de los profesionales. Inicialmente, se evaluó el rendimiento cognitivo en una prueba de opción múltiple sobre la respuesta a una parada cardiorrespiratoria (PCR) y luego se llevó a cabo una PCR llamada simulada, para la evaluación de habilidades, usando un checklist basado en las recomendaciones de la American Heart Association (AHA). Después de la evaluación inicial, todos los profesionales participaron en el curso teórico y práctico en SVB durante tres reuniones. Después del curso, todos fueron sometidos a una evaluación adicional. Resultados: El estudio incluyó 32 profesionales. El nivel de conocimientos y habilidades eran pobres antes del curso. Después de la capacitación, la puntuación promedia en la evaluación escrita y práctica mostró un aumento significativo $(p<0,001)$. Conclusión: Se registró impacto positivo de la formación en SVB para los profesionales de atención primaria.

Como citar: Meira Júnior LE, Souza FM, Almeida LC, Veloso GGV, Caldeira AP. Avaliação de treinamento em suporte básico de vida para médicos e enfermeiros da atenção primária. Rev Bras Med Fam Comunidade. 2016;11(38):1-10. http://dx.doi.org/10.5712/rbmfc11(38)1231
Palavras-chave: Educação em Saúde Reanimação Cardiopulmonar Atenção Primária à Saúde

Keywords: Heath Education Cardiopulmonary Resuscitation Primary Health Care

Palabras clave: Educación en Salud Resucitación Cardiopulmonar Atención Primaria de Salud

Fonte de financiamento: declaram não haver.

Parecer CEP: 261.476 (FIPMoc), aprovado 02/05/2013.

Conflito de interesses: declaram não haver. Procedência e revisão por pares: revisado por pares. Recebido em: 21/10/2015. Aprovado em: 09/09/2016. 


\section{Introdução}

As doenças cardiovasculares correspondem a um terço do total de óbitos por causas definidas no Brasil, representando a principal causa de morte na população geral. ${ }^{1} \mathrm{E}$, muitas vezes, têm como desfecho final a parada cardiorrespiratória (PCR), com ausência súbita de pulso em grandes artérias e perda da consciência. O reconhecimento de tal situação e a realização precoce das manobras de ressuscitação cardiopulmonar (RCP) são fundamentais para a sobrevida dos pacientes. Torna-se, então, necessário que o profissional de saúde identifique prontamente tal situação e adote as medidas iniciais de reanimação, trabalhando em equipe, seguindo os protocolos específicos e aprimorando seus conhecimentos por meio de programas de atualização e treinamento em RCP. ${ }^{2}$

Apesar da literatura científica oferecer contínuas atualizações sobre a prevenção e abordagem à PCR, muitas vidas são perdidas no Brasil por falta de atedimento oportuno. O atendimento imediato e adequado à vítima de PCR que, em cerca de $50 \%$ dos casos, ocorre fora do ambiente hospitalar é fundamental para definir sua sobrevida. ${ }^{3}$

Tem-se observado que muitos profissionais da saúde possuem deficiência tanto no conhecimento quanto na prática de situações de emergência. ${ }^{4} \mathrm{O}$ desconhecimento sobre os sintomas e a subestimação dos casos podem implicar em atraso no trabalho das equipes socorristas. ${ }^{5} \mathrm{O}$ treinamento sistemático de profissionais de saúde pode duplicar ou triplicar as chances de sobrevivência em uma PCR, independentemente do local de atendimento, inclusive em ambientes extra-hospitalares. ${ }^{6}$

Em 2006, o Brasil definiu a Estratégia Saúde da Família (ESF) como principal ferramenta de operacionalização da atenção primária, como ponto de contato preferencial e porta de entrada de uma rede de serviços universal, com responsabilidade para coordenar os cuidados e efetivar a integralidade nas diversas dimensões. ${ }^{7}$ Como porta de entrada no sistema de saúde e com a expansão desses serviços, os profissionais das equipes de Saúde da Família têm sido cada vez mais demandados para atendimento oportuno e estabilização de pacientes graves, incluindo-se aqueles em PCR.

É preciso, então, conhecer a competência destes profissionais na realização das manobras de RCP, identificando o conhecimento e habilidades para atuação e a necessidade de programas de treinamento. Um recente estudo europeu destaca a importância de treinamentos específicos para profissionais da atenção primária. ${ }^{8}$ Existem evidências de que pessoas bem treinadas, inclusive em ambientes comunitários, podem contribuir efetivamente para o sucesso das manobras de ressuscitação. ${ }^{5,8}$

Embora seja senso comum que programas de treinamento possuam alguma efetividade, é necessário avaliar o resultado real de treinamentos teórico-práticos para as equipes da Atenção Primária, identificando a necessidade de institucionalizar capacitações similares. O presente estudo objetivou avaliar conhecimentos e habilidades técnicas de reanimação cardiopulmonar antes e após um curso de capacitação em Suporte Básico de Vida (SBV) para médicos e enfermeiros que atuam na Estratégia Saúde da Família.

\section{Métodos}

Trata-se de um estudo de intervenção, com uma abordagem quasi-experimental desenvolvido em um Laboratório de Simulações de Urgências (LabSim), em Montes Claros, MG, no período de agosto a dezembro de 2013. Os participantes do estudo foram profissionais de saúde de nível superior selecionados 
aleatoriamente a partir da relação de todos os profissionais médicos e enfermeiros atuantes nas equipes da ESF do município. No período do estudo, havia 59 médicos e 70 enfermeiros cadastrados. Para a seleção dos profissionais, utilizou-se um programa gerador de números aleatórios, atribuindo-se um número para cada profissional.

Para o cálculo amostral, foram utilizados os seguintes parâmetros: nível de significância de $5 \%$, poder do estudo de $80 \%$, taxa de resposta (acertos) inicial de 30\% (pois define o maior número amostral) e diferença na taxa de resposta de 35\%. Esse cálculo definiu o número mínimo de 32 profissionais, em um teste uni-caudal.

Todos os profissionais - médicos e enfermeiros - efetivamente atuantes em equipes de Saúde da Família há, pelo menos, seis meses foram elegíveis para o estudo e, portanto, envolvidos no processo de seleção aleatória. Foram excluídos profissionais que recusaram assinar o Termo de Consentimento Livre e Esclarecido (TCLE), que se encontravam afastados das suas atividades de trabalho e aqueles que, por situações especiais, apresentavam dificuldades para desempenho das atividades práticas (uma profissional foi excluída por estar em fase final da gestação e outra por ser paraplégica). Para análise estatística, foram excluídos os profissionais que não compareceram a todas as etapas do trabalho.

O estudo seguiu as normas da resolução 466/12 e foi conduzido após a aprovação por Comitê de Ética em Pesquisa (Parecer no 261.476). Todos os participantes foram informados sobre o trabalho e registraram sua aquiescência em participar do estudo, assinando o TCLE.

Os participantes foram divididos em turmas de até oito profissionais e cada turma participou de três encontros, sendo um a cada semana. Optou-se por trabalhar com grupos pequenos para se atingir um melhor aproveitamento nas atividades práticas. No primeiro encontro, os profissionais foram submetidos a um questionário para avaliar características sociodemográficas, tais como: sexo, idade, tempo de formado, informações sobre pós-graduação e capacitações prévias. Em seguida, os profissionais foram apresentados aos materiais utilizados na simulação clínica por meio de orientações junto ao manequim de RCP Resusci Anne com PC Skillreporting System (Laerdal Medical Corporation, Stavanger, Norway), assim como os insumos necessários ao atendimento do caso proposto.

Ainda neste primeiro encontro, os participantes foram solicitados a atender uma situação simulada de PCR: foram conduzidos individualmente a uma sala, onde foram apresentados a um caso de um paciente irresponsivo encontrado na unidade de saúde no final do expediente. O atendimento ao caso foi submetido à avaliação, a partir de um checklist (Quadro 1) previamente desenvolvido por três especialistas, com base nas recomendações da AHA para o curso Basic Life Support (BLS). ${ }^{9}$

Em seguida, os participantes foram submetidos a um teste composto por 20 questões de múltipla escolha, com 5 opções de respostas, em que foram avaliados os conhecimentos sobre o atendimento à PCR. O teste foi elaborado segundo as diretrizes da AHA, ${ }^{9}$ utilizadas nos cursos específicos da instituição. Foram elaboradas dez questões abordando aspectos gerais de um atendimento à PCR e dez questões abordando especificamente os aspectos da técnica a ser empregada. Para a avaliação de desempenho, cada questão corretamente respondida equivalia a um ponto no escore geral do respondente. Concluindo esse primeiro encontro, os profissionais selecionados participaram de uma atividade teórica com quatro horas de duração nos moldes do curso de SBV desenvolvido pela AHA.

O segundo encontro, realizado na semana seguinte, consistiu de aula prática com a demonstração de todos os procedimentos nos manequins de simulação de baixa e média fidelidade para treinamento 
Quadro 1. Checklist para avaliação de habilidades práticas em atendimento à parada cardiorrespiratória.

\begin{tabular}{|l|}
\hline Ações \\
\hline 1 - Testou responsividade? \\
2 - Acionou ajuda (192)? \\
3 - Iniciou o atendimento com C-A-B? \\
4 - Checou o pulso central (5 a 10 seg.) como primeira ação? \\
5 - Se pulso ausente, iniciou compressão torácica? \\
6 - Localizou posição adequada para compressão? \\
7 - Posicionou as mãos de forma adequada? \\
8 - Realizou compressão de forma adequada (Depressão de 5cm do esterno, Frequência de no mínimo \\
$100 /$ mim. e Retorno completo do tórax)?. \\
9 - Realizou compressão e ventilação de forma adequada (relação 30:2)? \\
10 - Checou se o paciente ventilava de forma adequada, quando ofertada ventilação? Incluir a verificação \\
do posicionamento adequado das mãos e da máscara. \\
11 - Aplicou DEA da forma correta e obedeceu aos comandos? \\
12 - Aplicou desfibrilação quando indicado? \\
13 - Retornou às compressões imediatamente após a desfibrilação? \\
14 - Quando não indicado choque, checou pulso? \\
15 - Com o Retorno da Circulação Espontânea (RCE) fez a reavaliação (ABCDE)? \\
16 - Após RCE colocou paciente em posição de recuperação?
\end{tabular}

de habilidades e no manequim de RCP, com duração de quatro horas. Todos os participantes praticaram nos manequins, de forma individual e coletiva, tiraram dúvidas e realizaram simulações de casos clínicos. Foram apresentados e disponibilizados materiais para estudo, como textos, protocolos e vídeos da AHA, demonstrando as atividades práticas descritas nos protocolos.

O terceiro encontro consistiu em nova realização do teste de conhecimentos aplicado no primeiro encontro e na realização do segundo atendimento simulado. Nesta fase, foram também registrados os dados referentes ao atendimento pós-capacitação, utilizando o mesmo checklist empregado na primeira avaliação, e comparados com os resultados obtidos antes da capacitação.

O Quadro 2 sintetiza as atividades desenvolvidas no processo de capacitação dos profissionais.

A avaliação de impacto foi conduzida por meio de análise dos desempenhos nas manobras de RCP antes e após a capacitação. As médias nos testes foram comparadas com o uso do teste Wilcoxon, assumindo-se um nível de significância de 5\%. Para as análises estatísticas, utilizou-se o software IBM SPSS Statistics, versão 20 (SPSS 20).

\section{Resultados}

Participaram do estudo 36 profissionais de saúde, contudo, 4 deles não cumpriram todas as etapas do estudo e foram excluídos das análises. A caracterização dos 32 participantes que concluíram o estudo é apresentada na Tabela 1.

Houve pequeno predomínio de enfermeiros e a maioria dos participantes era do sexo feminino. A média de idade foi de $30,8 \pm 6,1$ anos, enquanto o tempo de trabalho na ESF dos profissionais mostrou grande variabilidade $(49,4 \pm 43,2$ meses). 
Quadro 2. Atividades desenvolvidas no processo de capacitação dos profissionais.

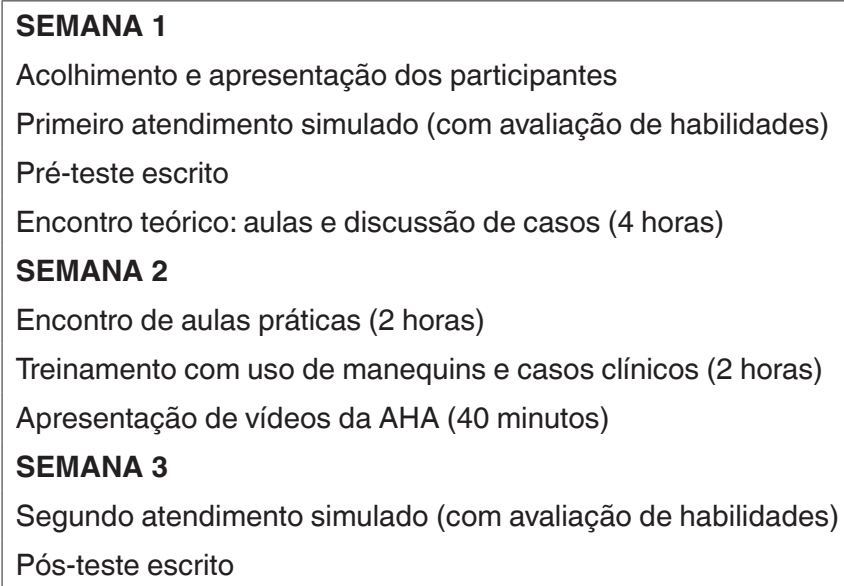

Tabela 1. Características dos participantes da capacitação em Suporte Básico de Vida; Montes Claros (MG), 2013.

\begin{tabular}{|c|c|c|}
\hline Variáveis & (n) & $(\%)$ \\
\hline \multicolumn{3}{|l|}{ Profissão } \\
\hline Médicos & 14 & 43,8 \\
\hline Enfermeiros & 18 & 56,2 \\
\hline \multicolumn{3}{|l|}{ Gênero } \\
\hline Masculino & 6 & 18,8 \\
\hline Feminino & 26 & 81,2 \\
\hline \multicolumn{3}{|l|}{ Idade (anos) } \\
\hline $21-25$ & 6 & 18,8 \\
\hline $26-30$ & 12 & 37,5 \\
\hline $31-35$ & 9 & 28,0 \\
\hline$\geq 36$ & 5 & 15,7 \\
\hline \multicolumn{3}{|c|}{ Tempo desde a formatura (meses) } \\
\hline$<24$ & 7 & 21,9 \\
\hline $25-60$ & 11 & 34,3 \\
\hline$\geq 60$ & 14 & 43,8 \\
\hline \multicolumn{3}{|c|}{ Tempo atuando na ESF (meses) } \\
\hline$<24$ & 15 & 46,9 \\
\hline $25-60$ & 5 & 15,6 \\
\hline$\geq 60$ & 12 & 37,5 \\
\hline \multicolumn{3}{|c|}{ Possuem residência (médica ou multiprofissional) } \\
\hline Sim & 19 & 59,4 \\
\hline Não & 13 & 40,6 \\
\hline \multicolumn{3}{|c|}{ Possuem outra pós-graduação } \\
\hline Sim & 12 & 37,5 \\
\hline Não & 20 & 62,5 \\
\hline
\end{tabular}

A Tabela 2 apresenta características do grupo em relação à capacitação para atendimentos de urgência e emergência. Apenas 12 profissionais (37,5\%) já haviam realizado alguma capacitação em urgência. Sete participantes $(21,9 \%)$ relatam ter tido uma experiência prévia satisfatória com algum caso de reanimação cardiopulmonar e $23(71,9 \%)$ deles declararam que se sentiam ansiosos ou muito ansiosos sobre os 
procedimentos do curso. Quase a totalidade dos participantes $(93,8 \%)$ considerava o treinamento útil ou muito útil. Nenhuma das variáveis estudadas mostrou-se associada a melhor desempenho na assistência simulada ou no teste antes ou após a capacitação realizada.

A Tabela 3 mostra a nota média dos profissionais separados por desempenho cognitivo (aspectos gerais e aspectos técnicos) e por habilidades práticas. Antes da realização do curso, os aspectos gerais do tema tiveram o pior desempenho por parte do grupo. A questão relacionada à fisiopatologia da PCR foi a que obteve menor pontuação, enquanto as questões relacionadas às compressões torácicas (aspectos técnicos) foram as que propiciaram maiores escores. Mesmo após o curso, a questão relacionada à fisiopatologia, apesar de ter tido o maior aumento absoluto na nota média, continuou sendo aquela com menor pontuação. A média de acertos para os aspectos gerais e técnicos avaliados apresentou aumento significativo após a capacitação $(p<0,001)$.

Em relação à avaliação da atividade prática simulada antes do curso, os principais erros observados se encontraram nas atividades referentes ao posicionamento das mãos para realização das compressões torácicas, assim como a profundidade e frequência das mesmas. Dificuldades para realização das ventilações,

Tabela 2. Variáveis relacionadas à capacitação em urgência/emergência para profissionais da Estratégia Saúde da Família; Montes Claros (MG), 2013.

\begin{tabular}{lcc}
\hline Variáveis & (n) & (\%) \\
\hline Capacitação prévia em urgência/emergência & & 37,5 \\
\hline Sim & 12 & 62,5 \\
Não & 20 & 21,9 \\
\hline Experiência prévia com reanimação cardiopulmonar & & \\
\hline Positiva ou satisfatória & 7 & \\
Pouco positiva ou pouco satisfatória & 15 & 31,2 \\
Nenhuma/não respondeu & 10 & 21,9 \\
\hline Sentimento prévio em relação ao curso & 6,2 \\
\hline Tranquilo & & \\
Não sei responder & 7 & 59,4 \\
Preocupado/Ansioso & 2 & 12,5 \\
Muito preocupado/Muito ansioso & 19 & \\
\hline Percepção prévia sobre o tema para o trabalho & 4 & 8,2 \\
\hline Não sei responder & & 8,4 \\
Muito útil & 2 & 9,4 \\
Útil & 27 & 3 \\
\hline
\end{tabular}

Tabela 3. Desempenho antes/depois da capacitação em Suporte Básico de Vida para profissionais da Estratégia Saúde da Família; Montes Claros (MG), 2013.

\begin{tabular}{|c|c|c|c|c|c|c|c|c|c|}
\hline \multirow{2}{*}{ Desempenho Cognitivo } & \multicolumn{4}{|c|}{ Antes } & \multicolumn{4}{|c|}{ Depois } & \multirow{2}{*}{ p-valor* } \\
\hline & Min & Max & Média & $D P^{* *}$ & Min & Max & Média & $\mathrm{DP}^{\dagger}$ & \\
\hline Aspectos Gerais & 2 & 9 & 6,0 & 1,7 & 7 & 10 & 8,6 & 1,0 & $<0,001$ \\
\hline Aspectos técnicos & 3 & 9 & 7,4 & 1,4 & 7 & 10 & 9,2 & 1,0 & $<0,001$ \\
\hline Habilidades & 2 & 15 & 8,0 & 3,4 & 9 & 16 & 13,7 & 1,8 & $<0,001$ \\
\hline
\end{tabular}


o não retorno imediato para compressão após a entrega do choque do Desfibrilador Externo Automático (DEA) e o desconhecimento sobre o que fazer após a recuperação do paciente também foram aspectos negativos bastante evidentes. Após o curso, houve melhora significativa em todos os itens. O desempenho dos profissionais nas atividades práticas simuladas também registrou melhora significativa $(p<0,001)$.

\section{Discussão}

O atendimento à urgência, incluido-se aí a PCR, é um aspecto inerente à prática do profissional de saúde e demanda treinamento regular e oportuno. Promover a capacitação de profissionais da atenção primária para a realização de adequadas manobras de rescuscitação é reconhecer a relevância da prestação de assistência integral, indepedentemente do nível ou do ambiente de cuidado. ${ }^{10}$ Quando não há conhecimento e treinamento mínimo para o atendimento sistematizado e efetivo a uma PCR, começam a ocorrer as falhas e a crescer o número de iatrogenias. ${ }^{11}$ Nesse tipo de situação, o tempo é fator primordial, exigindo preparo técnico e psicológico para que as medidas iniciais de suporte sejam tomadas de forma adequada, reduzindo o risco de óbito.

No presente estudo, registraram-se conhecimentos e habilidades insatisfatórios para os profissionais da ESF. Esse resultado aponta uma situação crítica em relação ao potencial de recuperação de pacientes assistidos durante uma PCR por tais equipes, pois cada minuto sem intervenção adequada reduz as chances de sobrevida em, aproximadamente, $10 \% .{ }^{5}$ Outro fator de impacto é a qualidade das manobras realizadas, pois pacientes vítimas de PCR quando submetidos rapidamente a manobras de qualidade têm três vezes mais chance de sobreviver. ${ }^{12}$

Desempenho insatisfatório em testes de conhecimento sobre atendimento à PCR já foi identificado mesmo em equipe multidisciplinar de hospital de alta complexidade. ${ }^{13}$ Estudo realizado com médicos de hospitais gerais do Paraná também revelou desempenho abaixo do esperado, destacando a necessidade de atualizações para os profissionais para o atendimento de situações de emergência. ${ }^{14}$

Especificamente em relação aos médicos, os resultados de estudos conduzidos na região Norte do Brasil evidenciaram deficiências no conhecimento de médicos atuantes em unidades de atendimento às urgências e os autores destacaram a necessidade de capacitação das equipes de saúde. ${ }^{15,16}$

No presente estudo, não foram realizadas análises distintas para as duas categorias profissionais, médicos e enfermeiros, pois entende-se que ambos devem ser igualmente habilitados para os primeiros socorros ao paciente vítima de PCR ${ }^{1}$. Um estudo recente conduzido em São Paulo mostrou um bom desempenho após treinamento para estudantes de diversas áreas da saúde, destacando a importância de capacitação conjunta da equipe de saúde. ${ }^{17}$

Os resultados da primeira etapa deste estudo apontaram falhas entre os profissionais que trabalham na ESF em oferecer o primeiro atendimento, de forma adequada, a uma vítima de PCR. Diante de uma situação simulada, o grupo estudado apresentou dificuldade em demonstrar conhecimentos práticos sobre $\mathrm{RCP}$, sobretudo em relação às habilidades de posicionamento correto das mãos, profundidade e frequência das compressões, posicionamento para ventilações e, principalmente, o manuseio do Desfibrilador Externo Automático (DEA). 
Os resultados são preocupantes, porque, diante da expansão da ESF no país, cada vez mais provável se tornará o evento PCR para os profissionais que atuam nessas equipes. Mesmo sem acesso ao DEA, inexistente na maioria das Unidades Básicas de Saúde, os profissionais de saúde devem estar em condições de efetuar um atendimento imediato adequado à vítima de PCR, o que tem sido recomendado mesmo para a população leiga em outros países. ${ }^{18}$

Estudos conduzidos em outros países já destacaram a relevância do treinamento de profissionais da APS para assistência imediata à PCR. ${ }^{19-21}$ Ainda existem poucos estudos no Brasil que abordam conhecimentos de profissionais da APS em relação ao atendimento de situações de urgência e emergência, em especial à PCR. ${ }^{11,22}$

No presente estudo, também se registrou um impacto positivo da capacitação em Suporte Básico de Vida. Esse aspecto é relevante e aponta a necessidade de capacitação para esse público. A eficácia da RCP está diretamente relacionada ao rápido reconhecimento da PCR e o início imediato das manobras, sendo fundamental o tempo e a qualidade das manobras. Entretanto, muitas vezes, a falta de capacitação retarda a reanimação até a chegada de um profissional da urgência pré-hospitalar, o que impacta de forma negativa na sobrevida dos pacientes. ${ }^{23}$

É relevante observar que, entre o grupo de profissionais que participaram do estudo, alguns informaram que já haviam realizado treinamento prévio, mas essa variável não se mostrou associada a melhor desempenho. Esse resultado, em princípio, torna natural a interpretação de que a capacitação não teria impacto sobre o desempenho dos profissionais. Entretanto, não foram investigadas as condições de capacitação prévia, as técnicas utilizadas, a carga horária do treinamento ou o tempo decorrido desde a última capacitação. Todas essas variáveis interferem sobre os resultados, incluindo a retenção de conhecimentos e habilidades a curto e a longo prazo.

Estudos sobre treinamento em SBV em diferentes locais e com públicos diferentes apontam resultados positivos. 11,13,17 Deve-se destacar, por outro lado, que a retenção dos conhecimentos e das habilidades adquiridas nos cursos de capacitação podem ser perdidas a longo prazo e há necessidade de atividades de reforço para os profissionais.

Os resultados deste estudo devem ser considerados à luz de algumas limitações. Não houve adesão de todos os profissionais inicialmente abordados. Embora o número de profissionais que permaneceram em todas as etapas do estudo tenha sido suficiente para assegurar o poder do estudo, segundo o cálculo amostral, o abandono de quatro profissionais pode ter gerado um resultado mais distante da situação real.

Outro aspecto é relativo à avaliação apenas imediata do resultado da capacitação, não tendo sido realizada a reavaliação dos profissionais seis meses após o curso para identificar a retenção dos conhecimentos e habilidades. Novos estudos deverão se ocupar dessa lacuna do conhecimento, que não foi possível de ser conduzida no presente estudo, pela elevada rotatividade dos profissionais da atenção primária, na região avaliada.

Também é importante destacar que melhores desempenhos após as atividades de capacitação não implicam em efetiva melhora da assistência à PCR. Nesse sentido, novos estudos devem ser desenvolvidos buscando identificar o impacto das capacitações sobre as taxas de mortalidade ou de reversão dos quadros de PCR assistidos pelas equipes capacitadas. 


\section{Conclusão}

As Unidades Básicas de Saúde (UBS) são consideradas portas de entrada do sistema e muitas vezes os profissionais que trabalham nestas unidades se deparam com situações de urgência e emergência sem estar devidamente preparados para este tipo de atendimento. Os resultados deste estudo sugerem que treinamentos com uso de simulações semirrealistas são efetivos para melhorar o conhecimento e as habilidades de profissionais da APS. Recomenda-se que esses profissionais participem de treinamentos frequentes para estarem aptos permanentemente ao atendimento de situações de urgência e emergência, incluindo a PCR, em seus locais de trabalho.

\section{Referências}

1. Morais DA, Carvalho DV, Correa AR. Parada cardíaca extra-hospitalar: fatores determinantes da sobrevida imediata após manobras de ressuscitação cardiopulmonar. Rev Latino-Am Enfermagem. 2014;22(4):562-8. DOI: http://dx.doi. org/10.1590/0104-1169.3453.2452

2. Lima SG, Macedo LA, Lima Vidal M, Sá MPBO. Educação Permanente em SBV e SAVC: impacto no conhecimento dos profissionais de enfermagem. Arq Bras Cardiol. 2009;93(6):630-6. DOI: http://dx.doi.org/10.1590/S0066782X2009001200012

3. Gonzalez MM, Timerman S, Oliveira RG, Polastri TF, Dallan LAP, Araújo S, et al. I Diretriz de Ressuscitação Cardiopulmonar e Cuidados Cardiovasculares de Emergência da Sociedade Brasileira de Cardiologia: Resumo Executivo. Arq Bras Cardiol. 2013;100(2):105-13. DOI: http://dx.doi.org/10.5935/abc.20130022

4. Lyra PF, Cordeiro DEF, Gois ACR, Muniz FN, Leônidas GM, Rodrigues Sobrinho CRM. Programa de Educação em Reanimação Cardiorrespiratória: Ensinando a Salvar Vidas. Rev Bras Educ Med. 2012;36(4):570-3. DOI: http://dx.doi. org/10.1590/S0100-55022012000600018

5. Gonzalez MM, Timerman S, Gianotto-Oliveira R, Polastri TF, Canesin MF, Schimidt A et al. I Diretriz de ressuscitação cardiopulmonar e cuidados cardiovasculares de emergência da Sociedade Brasileira de Cardiologia. Arq Bras Cardiol. 2013;101(2 Suppl 3):1-221. DOI: http://dx.doi.org/10.5935/abc.2013S006

6. Boaventura AP, Miyadahira AMK. Programa de capacitação em ressuscitação cardiorrespiratória com uso do desfibrilador externo automático em uma universidade. Rev Gaúch Enferm. 2012;33(1):191-4.

7. Giovanella L, Mendonça MHM, Almeida PF, Escorel S, Senna MCM, Fausto MCR, et al. Saúde da família: limites e possibilidades para uma abordagem integral de atenção primária à saúde no Brasil. Ciênc Saúde Colet. 2009;14(3):783-94. DOI: http://dx.doi.org/10.1590/S1413-81232009000300014

8. Bury G, Egan M, Tobin H, Heaton M. Immediate care training in Ireland, 2002-2013: a potential link between high uptake rates and effect. Ir Med J. 2015;108(5):140-2

9. Berg RA, Hemphill R, Abella BS, Aufderheide TP, Cave DM, Hazinski MF, et al. Part 5: Adult Basic Life Support: 2010 American Heart Association Guidelines for Cardiopulmonary Resuscitation and Emergency Cardiovascular. Circulation. 2010;122(18 Suppl 3):S685-705. DOI: http://dx.doi.org/10.1161/CIRCULATIONAHA.110.970939

10. Barbosa MAF, Marra VR, Horta NC, Rodrigues ES. Capacitação dos profissionais de saúde para o atendimento de parada cardiorrespiratória na atenção primária. Rev APS. 2011;14(2):233-8.

11. Silva AR. Parada cardiorrespiratória em unidades de internação: vivências do enfermeiro [dissertação]. Ribeirão Preto: Escola de Enfermagem, Universidade de São Paulo; 2006.

12. Meissner TM, Kloppe $C$, Hanefeld C. Basic life support skills of high school students before and after cardiopulmonary resuscitation training: a longitudinal investigation. Scand J Trauma Resusc Emerg Med. 2012;20:31. DOI: http://dx.doi. org/10.1186/1757-7241-20-31

13. Veiga VC, Carvalho JC, Amaya LEC, Almeida Gentile JK, Rojas SSO. Atuação do Time de Resposta Rápida no processo educativo de atendimento da parada cardiorrespiratória. Rev Bras Clin Med. 2013;11(3):258-62. 
14. Knopfholz J, Lima Júnior E, Ribeiro APF, Boros GAB, Claviço J, Teider LD, et al. Manuseio de emergências cardiológicas em hospitais gerais do estado do Paraná. Rev Bras Clin Med. 2012;10(6):499-502.

15. Duarte RN, Fonseca AJ. Diagnóstico e tratamento de parada cardiorrespiratória: avaliação do conhecimento teórico de médicos em hospital geral. Rev Bras Ter Intensiva. 2010;22(2):153-8. DOI: http://dx.doi.org/10.1590/S0103$507 X 2010000200009$

16. Ferreira JVB, Ferreira SMB, Casseb GB. Perfil e Conhecimento Teórico de Médicos e Enfermeiros em Parada Cardiorrespiratória, município de Rio Branco, AC. Rev Bras Cardiol. 2012;25(6):464-70.

17. Kawakame PMG, Miyadahira AMK. Avaliação do processo ensino-aprendizagem de estudantes da área da saúde: manobras de ressuscitação cardiopulmonar. Rev Esc Enferm USP. 2015;49(4):657-64.

18. Dixe MACR, Gomes JCR. Conhecimento da população portuguesa sobre Suporte Básico de Vida e disponibilidade para realizar formação. Rev Esc Enferm USP. 2015;49(4):640-9.

19. Nurmi J, Castrén M. Preparedness for cardiopulmonary resuscitation in primary care. Scand J Prim Health Care. 2004;22(2):87-90. DOI: http://dx.doi.org/10.1080/02813430410006477

20. Ong ME, Yan X, Lau G, Tan EH, Panchalingham A, Leong BS, et al. Out-of-hospital cardiac arrests occurring in primary health care facilities in Singapore. Resuscitation. 2007;74(1):38-43. PMID: 17303304 DOI: http://dx.doi.org/10.1016/j. resuscitation.2006.11.004

21. Colquhoun M. Resuscitation by primary care doctors. Resuscitation. 2006;70(2):229-37. PMID: 16814447 DOI: http:// dx.doi.org/10.1016/j.resuscitation.2006.01.007

22. Silva CCS, Holanda AR. Parada Cardiorrespiratória: Conhecimento e Prática de uma Equipe de Saúde da Família. Rev Bras Ciênc Saúde. 2011;15(4):447-54.

23. Sasson C, Rogers MA, Dahl J, Kellermann AL. Predictors of survival from out-of-hospital cardiac arrest: a systematic review and meta-analysis. Circ Cardiovasc Qual Outcomes. 2010;3(1):63-81. DOI: http://dx.doi.org/10.1161/ CIRCOUTCOMES.109.889576

Luiz Ernani Meira Júnior. Programa de Pós-Graduação em Cuidados Primários em Saúde, Universidade Estadual de Montes Claros (Unimontes). Montes Claros, MG, Brasil. ernanimeirajr@ hotmail.com

Fabiane Mendes Souza. Faculdades Integradas Pitágoras. Montes Claros, Minas Gerais. Brasil. fah-mendes@ hotmail.com

Leonardo Canela Almeida. Faculdades Integradas Pitágoras. Montes Claros, Minas Gerais. Brasil. leocanela@msn.com

Gilson Gabriel Viana Veloso. Faculdades Integradas Pitágoras. Montes Claros, Minas Gerais. Brasil. gilson_1991@yahoo.com.br

Antônio Prates Caldeira. Programa de Pós-Graduação em Cuidados Primários em Saúde, Universidade Estadual de Montes Claros. Montes Claros, Minas Gerais. Brasil. antonio.caldeira@unimontes.br (Autor correspondente) 